\title{
Differentiating pelvic actinomycosis from advanced ovarian cancer: a report of two cases, management reflections and literature review
}

\author{
Alex Laios ${ }^{1 *}$, Iryna Terekh¹, Hooman Soleymani Majd ${ }^{1}$, Pubudu Pathiraja', Sanjiv Manek² and Krishnayan Haldar ${ }^{1}$
}

\begin{abstract}
Pelvic actinomycosis comprises a rare, subacute to chronic bacterial infection characterised by suppurative and granulomatous inflammation. Diagnosis is difficult as it may simulate pelvic malignancies. Laboratory and radiological findings are non-specific. We reported on 2 cases of pelvic actinomycosis mimicking ovarian malignancy with different management approaches that lead to opposite outcomes. We reviewed the literature on pelvic actinomycosis imitating ovarian cancer with a focus on its surgical management. Despite agreement on the duration of antibiotic therapy following surgical management, consensus regarding surgical approach was rather equivocal. We concluded that pelvic actinomycosis should be strongly suspected in women with presumed ovarian cancer of atypical presentation and a history of intrauterine devices (IUD).
\end{abstract}

\section{Background}

Actinomycosis comprises a subacute to chronic bacterial infection caused by filamentous, gram-positive, nonacidfast, anaerobic bacteria. It is characterised by contiguous, suppurative and granulomatous inflammation. Pelvic actinomycosis although rare, occurs almost only in women. It may simulate pelvic malignancies or retroperitoneal tumours [1], which often makes it difficult to diagnose. Pelvic organs can be affected leading to different clinical presentations. A high index of disease suspicion in patients with a history of intrauterine devices (IUD) can prevent unnecessary extensive surgical procedures [2]. Radiological findings are non-specific, however computed tomography (CT) appears to be the most useful imaging modality. We presented 2 case reports of pelvic actinomycosis with different management approaches that lead to opposite outcomes. We also conducted a literature review to add on the understanding of this rare disease.

\footnotetext{
* Correspondence: alex.laios@obs-gyn.ox.ac.uk

${ }^{1}$ Gynaecologic Oncology Unit, Churchill Hospital, Oxford University Hospitals, NHS Trust, Oxford, UK

Full list of author information is available at the end of the article
}

\section{Case presentation}

\section{Case report 1}

A 57-year old, mother of two, postmenopausal caucasian woman was referred to our centre following MDT discussion for a 4-month long, persistent, progressively worsening lower abdominal pain. This was associated with mild, offensive vaginal discharge but no vaginal bleeding. She had a significant weight loss (19 kg over 1 month), loss of appetite, dysuria and constipation. Her past medical history included bipolar disorder, hypothyroidism and hypertension. She had a recent psychotic episode following discontinuation of her medication due to lithium toxicity. She had no previous abdominal or pelvic surgeries, abdominal wall trauma or immunosuppression. The patient was previously on HRT for 8 years and had a copper IUD in situ for the last 9 years. Her family history was unremarkable.

Physical examination demonstrated a large abdominal mass protruding through the anterior abdominal wall between the umbilicus and symphysis pubis. She was afebrile and had mild generalised abdominal tenderness but no rigidity or guarding. Pelvic examination revealed a 20-week sized gravid uterus and a fixed solid abdominopelvic mass with no cervical motion tenderness. Laboratory investigations demonstrated mild anaemia ( $\mathrm{Hb}: 9 \mathrm{~g} / \mathrm{dL}$ ), raised CRP at $118 \mathrm{mg} / \mathrm{l}$ and leucocytosis (WCC $27 \times 10^{3} / \mu \mathrm{l}$ ). 
A pelvic US showed bilateral complex, predominantly cystic pelvic masses, inseparable from each other. This was confirmed by CT, which additionally reported a soft anterior abdominal wall mass $60 \times 25 \times 60 \mathrm{~mm}$ situated below the umbilicus involving the right rectus abdominis muscle. A small amount of fluid in the right paracolic gutter was seen in addition to generalised peritoneal disease and sigmoid involvement. The overall picture was suggestive of malignant ovarian disease (Figure 1a-b).

CA125 was $39 \mathrm{U} / \mathrm{ml}$, CEA and CA199 were normal. The patient was transfused preoperatively due to low haemoglobin and scheduled for an exploratory laparotomy preceded by laparoscopy. Unfortunately, due to deterioration of her symptoms, she underwent an emergency procedure. Following initial laparoscopic assessment to assess the disease operability, she underwent an en bloc pelvic resection with total abdominal hysterectomy and bilateral salpingo-ophorectomy, omentectomy, bladder peritonectomy, rectosigmoid resection with re-anastomosis and excision of an anterior abdominal wall tumour. Subsequently, she required a defunctioning stoma due to pelvic sepsis and partial closure of the abdominal defect with a prolene mesh. Further debridement was required, which was followed by a split skin graft from her right thigh. Histology revealed widespread abdominal and pelvic actinomycosis with a florid inflammatory and fibrotic response comprising of microabscesses (Figures 1c and 2). A tumour mass effect was seen (Figure 3). Active chronic inflammation in the endometrial cavity, most likely associated with the IUD was reported. She remained on IV benzylpenicillin $1.8 \mathrm{mg} / 4 \mathrm{~h}$ for a total of 6 weeks. She was discharged at 2 months with a low grade wound infection secondary to foreign mesh material reaction and a rather erratic colostomy performance required supportive management. She became systemically well. Oral amoxicillin $500 \mathrm{mg} 3$ times daily was initially considered until reversal of the colostomy. At 9 months follow-up, endoscopy showed mild active proctitis and as it deemed unsafe to restore GI continuity, a revision of her end colostomy with reconstruction of abdominal wall was undertaken. The total duration of oral antibiotics was 12 months.

\section{Case report 2}

A 37-year old, mother of two, caucasian woman was initially presented to the gastroenterology team for investigation of a 3-month long persistent, progressively worsening lower abdominal pain. This was severe in nature, predominant in the left flank, lasting for a few seconds and spontaneously resolving. It was associated with significant weight loss (15 kg over 2 months), pyrexia, night sweats, anorexia and altered bowel habits. Her medical history included asthma. She had no previous abdominal surgery, trauma or immunosuppression. She had a copper IUD in situ for 4 years. There was a family history of colon cancer and Crohn's disease.

On physical examination, there was no pyrexia. There was left flank and iliac fossa tenderness with no rigidity or guarding and mild left lower limb oedema. Pelvic examination revealed a tender, solid, fixed pelvic mass extending to the left pelvic side wall and the posterior sacral region. Doppler ultrasonography (US) of the left lower limb ruled out deep vein thrombosis and superficial thrombophlebitis. Laboratory investigations demonstrated

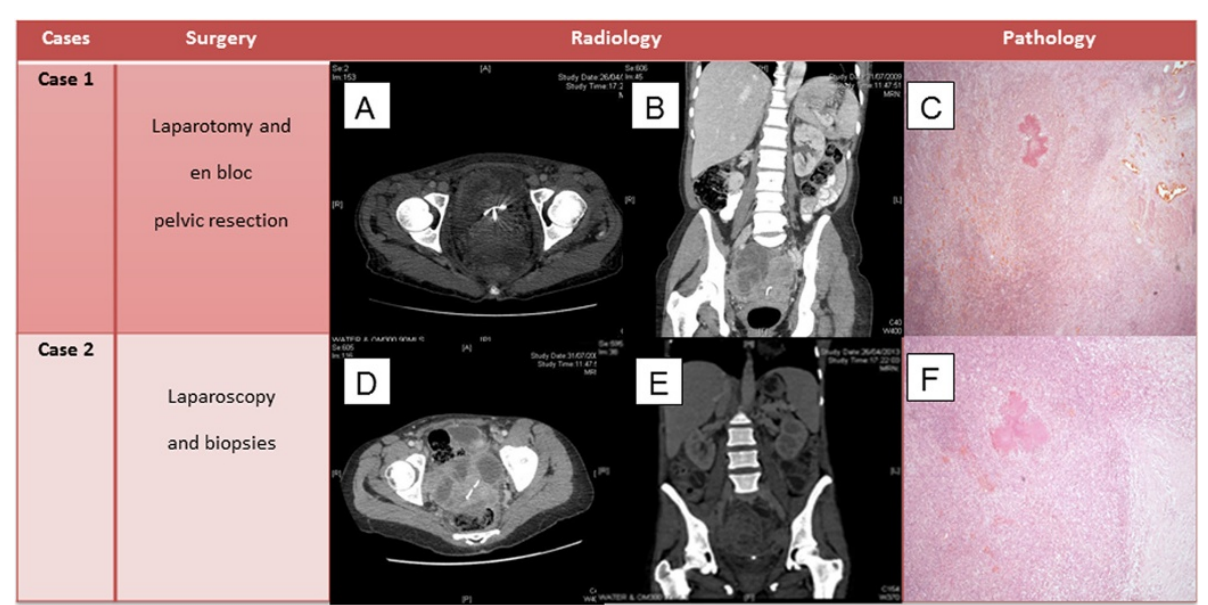

Figure 1 Surgical procedures, imaging and pathological findings. Case 1 - a) Axial preoperative abdominopelvic CT scan showing inseparable bilateral ovarian masses with coil in situ b) coronal view c) colony of Actinomyces organisms surrounded by inflammatory cells with adjacent fibrosis which had disrupted the smooth muscle of bowel wall rendering a 'mass' (H\&E stain, 10x). Case 2 - $\mathbf{d}$ ) preoperative abdominopelvic computed tomography (CT) scan showing right complex adnexal mass (axial) e) preoperative abdominopelvic CT showing presacral mass with IUD in situ (coronal) f) colony of Actinomyces surrounded by acute and chronic inflammatory cells. To the right of the image, there is fibrosis (H\&E stain, 10x). 


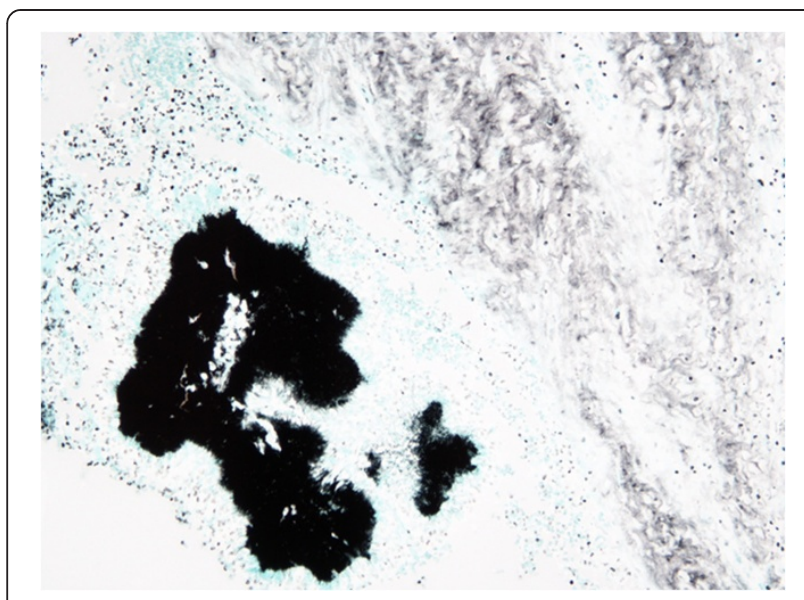

Figure 2 Colony of Actinomyces organisms (Grocott stain, 40x).

anaemia (Hb: $7.9 \mathrm{~g} / \mathrm{dL}$ ), raised CRP at $133 \mathrm{mg} / \mathrm{l}$ and leucocytosis (WCC $\left.14.3 \times 10^{3} / \mu \mathrm{l}\right)$.

Gastro-duodenoscopy revealed mild chronic gastritis and reactive gastropathy whilst colonoscopy ruled out the possibility of inflammatory bowel disease. CT thoraxabdomen-pelvis scan revealed a $75 \times 61 \mathrm{~mm}$ complex right adnexal mass and a $52 \times 41 \mathrm{~mm}$ heterogeneous presacral mass. Multiple smaller masses were seen in the left flank, left iliac fossa and anterior pelvis, consistent with metastatic disease (Figure 1d-e). Several loops of small bowel appeared to be tethered in the pelvis and were partially obstructed. The rectum was thought to be infiltrated by the pre-sacral mass. There were bilateral hydronephroses. There was small volume of ascites with some associated peritoneal enhancement and mild left pleural effusion with no evidence of lung parenchymal metastases.

The case was discussed at the gynaecologic oncology multidisciplinary team (MDT) due to high suspicion of

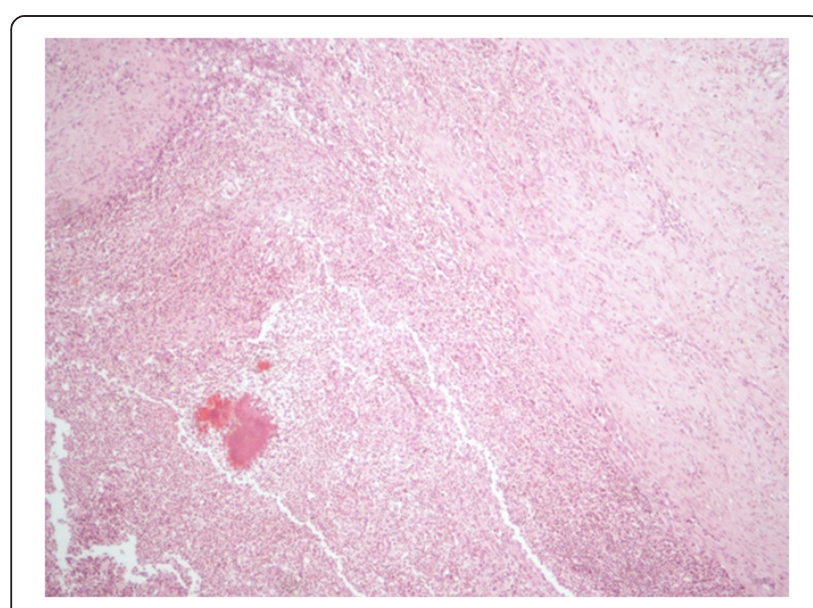

Figure 3 Mass effect. Another area in the exenteration sample in case 1 showing the inflammation and fibrosis which has caused a mass effect (H\&E stain, 10x). advanced ovarian cancer. Tumour markers included elevated CA125 at $83 \mathrm{U} / \mathrm{ml}, \mathrm{CA} 199$ at $51 \mathrm{U} / \mathrm{ml}$; AFP and CEA were normal. A US-guided percutaneous biopsy of the left adnexal mass was performed as per MDT decision, which was abandoned as there was no safe path to the lesion and hence diagnostic laparoscopy and biopsies were planned instead.

At laparoscopy, there were multiple omental and large bowel adhesions to the anterior and lateral abdominal wall. The right adnexal mass was not visualised as the adjacent small bowel was obscuring the right ovary. A left pelvic side wall biopsy was taken and ascitic fluid was drained. Histology confirmed a benign peritoneal nodule showing fibrosing inflammation in association with actinomyces colonies. The latter were surrounded by acute suppurative exudate within chronic inflammation and prominent foamy macrophages (Figure 1f). The fibrous band rendered a mass effect. No dysplasia or malignancy was present. Cytology was negative for malignancy too. This was therefore a case of severe pelvic inflammatory disease secondary to actinomyces infection. The patient made an uneventful recovery. She had a negative STD work-up and the IUD was removed. However, IUD culture failed to isolate actinomyces. Blood cultures were negative for bacteraemia. She was advised against reinsertion of the IUD.

The patient was commenced on intravenous (IV) benzylpenicilline $1.8 \mathrm{mg}$ 4-hourly followed by IV ceftriaxone $2 \mathrm{~g}$ daily for 6 weeks. She was then switched to oral amoxicillin $500 \mathrm{mg} 3$ times daily totalling 6 months. As a result, her weight increased steadily whilst her night sweats and abdominal discomfort subsided. All haematological parameters returned to normal. Abdominopelvic examination prior to discharge was unremarkable. She returned to follow-up appointments at 6 weeks and 6 months and was completely asymptomatic.

\section{Literature review}

We searched the MEDLINE and EMBASE databases for articles published between 1988 and 2013 using medical subject heading $(\mathrm{MeSH})$ terms. Key terms included "pelvic actinomycosis" and "ovar" cancer or tumour or carcinoma or neoplasm". The search was limited to the words "humans and adult female". Additional publications were identified via cross-referencing from reference lists within the retrieved publications. Only case series published in English language but with no geographical restrictions were included in the literature review.

\section{Results}

The electronic search initially yielded 36 citations. Eleven reports were published in language other than english. There were two duplicate studies. Five studies were unrelated after screening titles; one study was a review, 3 
studies referred to bladder cancer, intrauterine myomas and tubo-ovarian abscesses respectively and one study was on a pediatric patient. In 2 studies, abstracts were not available and they were further excluded. A total of 16 publications were finally included in the literature review (Figure 4). The main characteristics of those case report studies with an emphasis to their management are shown in Table 1.

\section{Discussion}

Our institution is a tertiary referral cancer centre; as large numbers of patients are referred with presumed metastatic ovarian or primary peritoneal cancer, it is important to determine the frequency and nature of diseases that mimic malignancy. In this context, pelvic actinomycosis, although difficult to diagnose by virtue of its rarity [18], should be included in the differential diagnosis of ovarian cancer, especially if atypical presentation occurs.

We reported 2 cases of women who were diagnosed with extensive pelvic actinomycosis following surgical intervention. All management decisions were MDT approved and documented in MDT proformas. Their different management demonstrates the importance of making the diagnosis in an evocative clinical context, performing the necessary investigations to confirm suspicions, favouring medical treatment and possibly reserving surgical treatment for specific situations (Figure 5).

Both patients had a long standing history of copper IUD use. Pelvic actinomycosis accompanied by IUD accounts for about 3\% of all actinomycosis [19]. Although uncommon, a long duration of IUD appears to confer the greatest risk [1]. Signs of infection such as fever, night sweats and leucocytosis also add suspicion towards an infective cause or accurately predict the severity of the condition [20]. In our cases, abdominopelvic pain associated with significant weight loss constituted the prominent symptoms. As ovarian malignancy was presumed in both cases, staging CT scans were included in the diagnostic work-up. CT findings although useful in the preoperative diagnosis were non-specific to differentiate between malignancy and actinomycocis. They are quite often, similar to those in Crohn's disease or intestinal tuberculosis. However, they might show the aggressive, infiltrative nature of the disease with disruption of tissue planes and demonstrate one or more solid masses with thickened walls [21]. The first patient was initially referred from a regional hospital for MDT discussion. In the light of suspected advanced ovarian cancer and while waiting for an elective procedure with the intention-to-treat, she deteriorated and transferred to our centre. She underwent an emergency laparoscopy proceeding to exploratory laparotomy with en bloc resection. In the absence of emergency, a more conservative surgical approach should have been pursued. Performing such an extensive operation in such an infected surgical field added to the complications encountered in the postoperative period. The learning experience from that first case was reflected on the MDT discussion of the second case, yet ovarian malignant disease was the working diagnosis. A biopsy taken at the time of a diagnostic laparoscopy confirmed actinomycosis infection [22]. Frozen section should be considered in cases

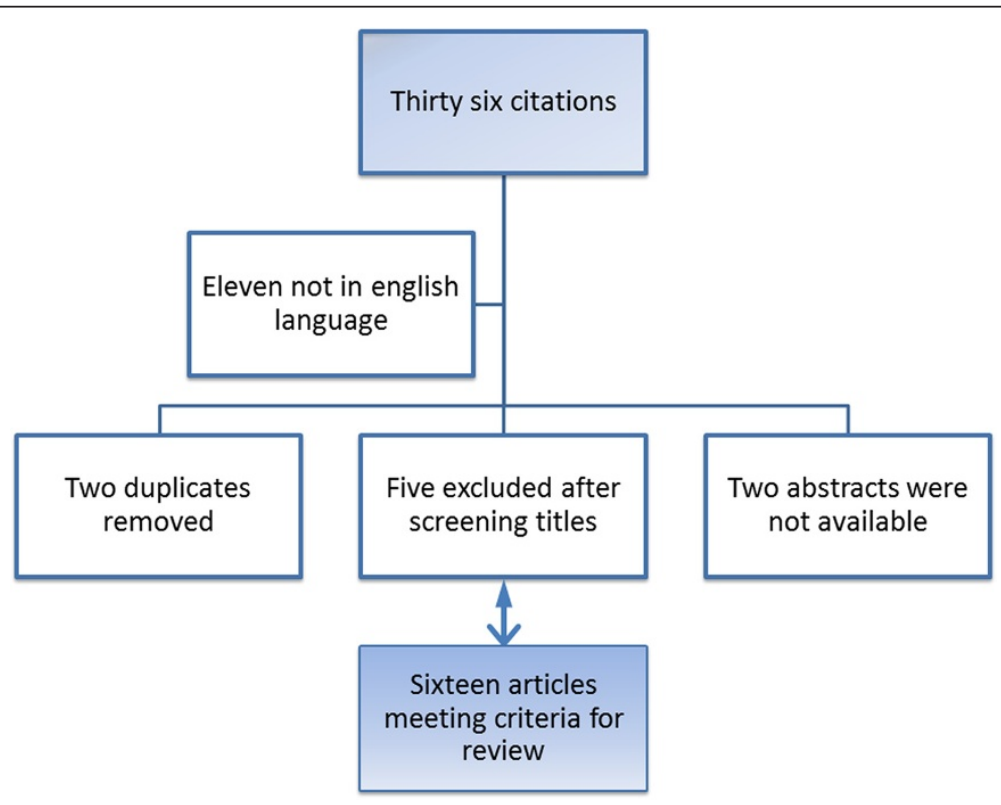

Figure 4 Comprehensive review selection strategy. 
Table 1 Case report studies on pelvic actinomycosis mimicking advanced ovarian cancer

\begin{tabular}{|c|c|c|c|c|}
\hline \multicolumn{5}{|c|}{ Case report studies on pelvic actinomycosis mimicking advanced ovarian cancer } \\
\hline Reference & $\begin{array}{c}\text { Age } \\
\text { (years) }\end{array}$ & Title & $\begin{array}{l}\text { Duration of copper } \\
\text { IUD (years) }\end{array}$ & $\begin{array}{l}\text { Diagnosis/Management algorithm/ } \\
\text { complications }\end{array}$ \\
\hline $\begin{array}{l}\text { Gungor T et al. [3], } \\
2013(n=1)\end{array}$ & 43 & $\begin{array}{l}\text { Pelvic actinomycosis: a disease that should } \\
\text { not be overlooked in cases with suspected } \\
\text { ovarian cancer }\end{array}$ & 7 & $\begin{array}{c}\text { Explorative laparotomy and debulking } \\
\text { surgery }\end{array}$ \\
\hline $\begin{array}{l}\text { Kim YS et al. [4], } \\
2012(n=1)\end{array}$ & 41 & $\begin{array}{c}\text { Metastatic hepatic actinomycosis } \\
\text { masquerading as distant metastases of } \\
\text { ovarian cancer }\end{array}$ & 15 & $\begin{array}{l}\text { Hepatic actinomycosis misdiagnosed as } \\
\text { distant metastases of ovarian cancer, } \\
\text { exploratory laparotomy with frozen section } \\
\text { of pelvic mass, penicillin totalling } 5 \text { months }\end{array}$ \\
\hline $\begin{array}{l}\text { Ong C et al. [5], } \\
2012(n=1)\end{array}$ & 73 & $\begin{array}{l}\text { Actinomyces turicensis infection mimicking } \\
\text { ovarian tumour }\end{array}$ & No IUD & $\begin{array}{l}\text { Pelvic mass and enlarged supraclavicular } L N \text {, } \\
\text { non-diagnostic FNA, blood cultures positive } \\
\text { for actinomyces, penicillin totalling } 7 \text { months }\end{array}$ \\
\hline $\begin{array}{l}\text { Pusiol T et al. [2], } \\
2011(n=1)\end{array}$ & 46 & $\begin{array}{l}\text { Abdomino-pelvic actinomycosis mimicking } \\
\text { malignant neoplasm }\end{array}$ & 3 & $\begin{array}{c}\text { Uncomplicated explorative laparotomy and } \\
\text { debulking surgery but incomplete staging, } \\
\text { penicillin totalling } 6 \text { months }\end{array}$ \\
\hline
\end{tabular}

Hwang JH et al. [6], $2010(n=1)$

Kumar $\mathrm{N}$ et al. [7], $2010(n=1)$

Lee YK et al. [8],

$2008(n=1)$

Akhan SE et al. [9], $2008(n=3)$

Kim HS et al. [10],

$2007(n=1)$

Sehouli J et al. [11],

$2006(n=1)$

Atay $Y$ et al. [12],

$2005(n=3)$

$37,45,47$

Oztekin $\mathrm{K}$ et al. [13],

$2004(n=1)$

Pelvic actinomycosis in a postmenopausal patient with systemic lupus erythematosus mimicking ovarian malignancy; case report and review of literature

Koshiyama $\mathrm{M}$ et al. [14], $1999(n=1)$

Primary serous papillary carcinoma of the peritoneum mimicking pelvic actinomycosis: a case report and brief literature review

32 Pelvic actinomycosis mimicking an advanced ovarian cancer

Pelvic actinomycosis with hydronephrosis and colon stricture simulating an advanced ovarian cancer

38, 37, 51 Pelvic actinomycosis mimicking ovarian malignancy: three cases

A case of pelvic actinomycosis with hepatic actinomycotic pseudotumor

Actinomycotic inflammatory disease and misdiagnosis of ovarian cancer

Ovarian actinomycosis mimicking malignancy

Ovarian actinomycosis complicated by diabetes mellitus simulating an advanced ovarian carcinoma

Hawnaur JM et al. [15]

$1999(n=1)$

Kirova YM et al. [16],

$1997(n=1)$

Magnetic resonance imaging of actinomycosis presenting as pelvic malignancy

IUD-associated pelvic actinomycosis: a rare disease mimicking advanced ovarian cancer; a case report

Hoffman MS et al., [17], $1991(n=2)$
Advanced actinomycotic pelvic inflammatory disease simulating gynecologic malignancy. A report of two cases.

Pelvic CT and MRI suggestive of pelvic actinomycosis. Full staging debulking surgery

confirmed primary peritoneal carcinoma

followed by adjuvant chemotherapy

No IUD

No IUD

IUD removed 4 months prior to admission, uncomplicated explorative laparotomy and debulking surgery, incomplete staging

maging guided needle biopsy made correct nonsurgical diagnosis, antibiotic treatment, no surgery required

Debulking surgeries in all cases, complete/ incomplete staging, second case was complicated by need for colostomy and fascial necrosis

FNA of hepatic tumour and explorative laparotomy of pelvis masses followed by penicillin totalling 4 months

Ureteric stenting followed by uncomplicated explorative laparotomy, patient received ampicillin and sulbactam totalling 6 weeks

Explorative laparotomy and intraoperative frozen section diagnosis of actinomycosis, long-term penicillin totalling 3 months

Rare occurrence of actinomycosis with an autoimmune disease that predisposed to infections, patient had laparotomy

No IUD MRI detected solid pelvic tumour mimicking advanced ovarian carcinoma invasive to bladder, rectum and uterus, patient denied initial explorative laparotomy, had neodjuvant chemotherapy followed by incomplete staging laparotomy and longterm penicillin, colostomy secondary to rectovaginal fistula

10

4

Plastic IUCD, 7, 17
MRI confirmed regression of pelvic disease in response to antibiotic therapy

$\mathrm{CT}$ detected pelvic mass with liver metastases mimicking advanced ovarian carcinoma, exploratory laparotomy and debulking surgery, incomplete staging

Laparotomy and long-term penicillin, some resolution of the pelvic fibrosis 


\begin{tabular}{|c|c|c|}
\hline Case 1 & & Case 2 \\
\hline 57 & Age (years) & 37 \\
\hline 9 & Duration of IUD use (years) & 4 \\
\hline Moderate & Abdominal pain & Moderate \\
\hline Severe & Weight loss & Severe \\
\hline Mild & $\begin{array}{l}\text { Abnormal vaginal } \\
\text { bleeding/discharge }\end{array}$ & None \\
\hline 9 & $\mathrm{Hb}(\mathrm{g} / \mathrm{dl})$ & 7.9 \\
\hline No & Pyrexia & No \\
\hline Mild & Ascites & Mild \\
\hline 39 & Ca125 (U/ml) & 83 \\
\hline 118 & CRP(mg/l) & 133 \\
\hline 27 & WCC $\left(x 10^{3} / \mu \mathrm{I}\right)$ & 14.3 \\
\hline Pelvic ultrasound, CT scan & Investigations & $\begin{array}{l}\text { CT scan, endoscopy, } \\
\text { colonoscopy }\end{array}$ \\
\hline 60 & Max size of pelvic mass (mm) & 75 \\
\hline $\begin{array}{l}\text { Laparotomy and en block } \\
\text { pelvic resection }\end{array}$ & Operative procedure & Laparoscopy and biopsies \\
\hline $\begin{array}{l}\text { Bilateral ovarian cysts, } \\
\text { rectosigmoid involvement, } \\
\text { abdominal wall lesion }\end{array}$ & Surgical findings & $\begin{array}{l}\text { Multiple adhesions, pelvic } \\
\text { side wall lesion }\end{array}$ \\
\hline Yes & Complications & No \\
\hline
\end{tabular}

Figure 5 Differentiation between the two reported cases with pelvic actinomycosis.

of atypical adnexal masses before undertaking extensive surgery [23]. Recently, a high detection rate of actinomyces by cytology has been suggested adding on the diagnosis [24].

Several case reports of pelvic actinomycosis mimicking ovarian malignancies have been published [3,25-27] and (Table 1). Pelvic actinomycosis has been known to present as a rectal mass with hydronephrosis [28], following hysteroscopic removal of IUD [29] or incarcerated inguinal hernia [30]. In the presence of an abdominopelvic mass with suspected deposits, laparoscopy was a less invasive approach of establishing a definitive diagnosis, thereby minimising the risk for mutilating surgery. In most reports pelvic actinomycosis was diagnosed in women younger than 50 years old, who would not benefit from extensive surgery, especially as medical treatment was likely to be successful. Adjuvant debulking surgery could have taken place later if medical treatment was unsuccessful or if the patient developed complications [31]. Nonetheless, Nagler suggested that patients may not respond well to antibiotics before lesion resection, possibly due to compartmentalisation of organisms within granulation tissue [32]. Aggressive surgical management including extensive surgery -full debulking- is overwhelmingly supported in the literature $[3,9,11,14,33,34]$ taking into consideration the extent of the disease and patient's condition (Table 1). Alternatively, incomplete staging may be offered $[2,7,16,17]$ as an intermediate approach with lower morbidity risk while histology is pending.

According to this review, there was no consensus with respect to surgical management of actinomycosis. Agreement came only with the approximate duration of antibiotic treatment. Once diagnosis was made, high-dose and longterm use of penicillin was recommended to eradicate actinomycosis. IV benzylpenicillin was administered daily for up to 6 weeks following surgery. Oral treatment should be continued for a period of at least 6 months due to low penetration in the fibrosis and the tendency to recur [4].

\section{Conclusion}

Despite advanced imaging and diagnostics, it is important to suspect actinomycosis in women who present with a presumed ovarian cancer and a history of IUD. This will spare patients from unnecessary, potentially extensive surgery.

\section{Consent}

Written informed consents were obtained from the patients for publication of their case report and accompanying images.

\section{Competing interests}

The authors declare that they have no competing interests.

\section{Authors' contributions}

$\mathrm{AL}$ conceived the subject of this manuscript, performed the literature review and drafted the manuscript. IT contributed to the written material and authored the manuscript. HSM selected the CT images and contributed to the written material. SM selected and described the histological images and revised the manuscript. PP and $\mathrm{KH}$ critically appraised and revised the manuscript. All authors read and approved the final manuscript.

\section{Acknowledgements}

We are grateful to our patients who agreed on the publication of their case reports and to all participating site staff. We would like to thank Professor Ahmed Ahmed and Miss Nicola Jones for helpful discussions. We also thank Zoe Risk for administrative support and proof editing. 


\section{Author details}

${ }^{1}$ Gynaecologic Oncology Unit, Churchill Hospital, Oxford University Hospitals, NHS Trust, Oxford, UK. ²Department of Cellular Pathology, Oxford University Hospitals, Oxford, UK.

Received: 15 May 2014 Accepted: 2 July 2014

Published: 10 December 2014

\section{References}

1. Westhoff C: IUDs and colonization or infection with Actinomyces. Contraception 2007, 75:S48-S50.

2. Pusiol T, Morichetti D, Pedrazzani C, Ricci F: Abdominal-Pelvic actinomycosis mimicking malignant neoplasm. Infect Dis Obstet Gynecol 2011, 2011:747059.

3. Gungor TC, Baser E, Sirvan L, Erdogan K: Pelvic actinomycosis: a disease that should not be overlooked in cases with suspected advanced ovarian cancer. J Obstet Gynaecol 2013, 33:212-213.

4. Kim YS, Lee BY, Jung MH: Metastatic hepatic actinomycosis masquerading as distant metastases of ovarian cancer. J Obstet Gynaecol Res 2012, 38:601-604.

5. Ong C, Barnes $S$, Senanayake S: Actinomyces turicensis infection mimicking ovarian tumour. Singapore Med J 2012, 53(1):e9-e11.

6. Hwang JH, Song SH, Kim KA, Shin BK, Lee JK, Lee NW, Lee KW: Primary serous papillary carcinoma of the peritoneum mimicking pelvic actinomycosis: a case report and brief literature review. Eur J Gynaecol Oncol 2010, 31:214-216.

7. Kumar N, Das P, Kumar D, Kriplani A, Ray R: Pelvic actinomycosis mimicking an advanced ovarian cancer. Indian J Pathol Microbio/ 2010, 53:164-165.

8. Lee YK, Bae JM, Park YJ, Park SY, Jung SY: Pelvic actinomycosis with hydronephrosis and colon stricture simulating an advanced ovarian cancer. J Gynecol Oncol 2008, 19:154-156.

9. Akhan SE, Dogan Y, Akhan S, lyibozkurt AC, Topuz S, Yalcin O: Pelvic actinomycosis mimicking ovarian malignancy: three cases. Eur J Gynaecol Oncol 2008, 29:294-297.

10. Kim HS, Park NH, Park KA, Kang SB: A case of pelvic actinomycosis with hepatic actinomycotic pseudotumor. Gynecol Obstet Invest 2007, 64(2):95-99.

11. Sehouli JSJ, Schlieper U, Kuemmel S, Henrich W, Denkert C, Dietel M, Lichtenegger W: Actinomycotic inflammatory disease and misdiagnosis of ovarian cancer. a case report. Anticancer Res 2006, 26:1727-1731.

12. Atay $Y$, Altintas A, Tuncer I, Cennet A: Ovarian actinomycosis mimicking malignancy. Eur J Gynaecol Oncol 2005, 26:663-664.

13. Oztekin K, Akerkan F, Yucebilgin MS, Kazandi M, Terek MC, Sendag F, Zekioglu O: Pelvic actinomycosis in a postmenopausal patient with systemic lupus erythematosus mimicking ovarian malignancy: case report and review of the literature. Clin Exp Obstet Gynecol 2004, 31:154-157.

14. Koshiyama M, Yoshida M, Fujii H, Nanno H, Hayashi M, Tauchi K, Kaji Y: Ovarian actinomycosis complicated by diabetes mellitus simulating an advanced ovarian carcinoma. Eur J Obstet Gynecol Reprod Biol 1999, 87:95-99.

15. Hawnaur JM, Reynolds K, McGettigan C: Magnetic resonance imaging of actinomycosis presenting as pelvic malignancy. Br J Radiol 1999, 72:1006-1011.

16. Kirova YM, Belda-Lefrère MA, Le Bourgeois JP: Intrauterine device-associated pelvic actinomycosis: a rare disease mimicking advanced ovarian cancer: a case report. Eur J Gynaecol Oncol 1997, 18:502-503.

17. Hoffman MS, Roberts WS, Solomon P, Gunasekarin S, Cavanagh D: Advanced actinomycotic pelvic inflammatory disease simulating gynecologic malignancy. a report of two cases. J Reprod Med 1991, 36:543-545.

18. Bernet C, De Brabant F, Gonzalez M, Jung B, Millet O: Pelvic actinomycosis: a misleading picture. Ann Fr Anesth Reanim 2010, 29(1):50-52.

19. Merki-Feld GS, Lebeda E, Hogg B, Keller PJ: The incidence of actinomyces-like organisms in Papanicolaou-stained smears of copper- and levonorgestrelreleasing intrauterine devices. Contraception 2000, 61:365-368.

20. Koo YJ, Kwon YS, Shim JU, Mok JE: Predictors associated with severity of pelvic actinomycosis. J Obstet Gynaecol Res 2011, 37:1792-1796.

21. Bae JH, Song R, Lee A, Park JS, Kim MR: Computed tomography for the preoperative diagnosis of pelvic actinomycosis. J Obstet Gynaecol Res 2011, 37:300-304.
22. Lee YC, Min D, Holcomb K, Buhl A, DiMaio T, Abulafia O: Computed tomography guided core needle biopsy diagnosis of pelvic actinomycosis. Gynecol Oncol 2000, 79:318-323.

23. Marret $\mathrm{H}$, Wagner $\mathrm{N}$, Ouldamer $\mathrm{L}$, Jacquet $\mathrm{A}$, Body G: Actinomycose pelvienne: est-ce prévisible? Gynecol Obstet Fertil 2010, 38:307-312.

24. Matsuda K, Nakajima H, Khan KN, Tanigawa T, Hamaguchi D, Kitajima M, Hiraki K, Moriyama S, Masuzaki H: Preoperative diagnosis of pelvic actinomycosis by clinical cytology. Int J Womens Health 2012, 4:527-533.

25. Acevedo F, Baudrand R, Letelier LM, Gaete P: Actinomycosis: a great pretender. case reports of unusual presentations and a review of the literature. Int J Infect Dis 2008, 12:358-362.

26. Baltoyiannis G, Skopelitou AS, Gloustianou G, Batsis C, Kappas AM: Pelvic actinomycosis mimicking frozen pelvis: report of an unusual case. J Obstet Gynaecol 2000, 20:548-549. 12.

27. Wadhwa N, Jain G, Panikar N: Actinomycotic oophoritis misdiagnosed as an ovarian tumor. J Obstet Gynaecol Res 2011, 37:969-970.

28. Yilmaz M, Akbulut S, Samdanci ET, Yilmaz S: Abdominopelvic actinomycosis associated with an intrauterine device and presenting with a rectal mass and hydronephrosis: a troublesome condition for the clinician. Int Surg 2012, 97:254-259.

29. Wunderink HF, Lashley EELO, van Poelgeest MIE, Gaarenstroom KN, Claas ECJ Kuijper EJ: Pelvic actinomycosis-like disease due to propionibacterium propionicum after hysteroscopic removal of an intrauterine device. J Clin Microbiol 2011, 49:466-468.

30. Dharmadhikari D, Dharmadhikari R, Macdonald J, Beukenholdt R: Intrauterine contraceptive device-related actinomycosis infection presenting as an incarcerated inguinal hernia. J Obstet Gynaecol Res 2007, 33:595-597.

31. Lely RJ, van Es HW: Case 85: pelvic actinomycosis in association with an intrauterine device. Radiology 2005, 236:492-494.

32. Nagler R, Peled M, Laufer D: Cervicofacial actinomycosis: a diagnostic challenge. Oral Surg Oral Med Oral Pathol Oral Radiol Endod 1997, 83:652-656.

33. Simsek A, Perek A, Cakcak IE, Durgun AV: Pelvic actinomycosis presenting as a malignant pelvic mass: a case report. J Med Case Reports 2011, 5:40.

34. de Feiter PW: Gastrointestinal actinomycosis: an unusual presentation with obstructive uropathy: report of a case and review of the literature. Dis Colon Rectum 2001, 44:1521-1525

\section{doi:10.1186/2053-6844-1-5}

Cite this article as: Laios et al:: Differentiating pelvic actinomycosis from advanced ovarian cancer: a report of two cases, management reflections and literature review. Gynecologic Oncology Research and Practice 2014 1:5.

\section{Submit your next manuscript to BioMed Central and take full advantage of:}

- Convenient online submission

- Thorough peer review

- No space constraints or color figure charges

- Immediate publication on acceptance

- Inclusion in PubMed, CAS, Scopus and Google Scholar

- Research which is freely available for redistribution 